\title{
Optimal Strategies for CLSC considering Supply Disruption and Carbon Tax
}

\author{
Lin Tong, Kuan Yang (D), and Wei-Jin Xu \\ School of Business Administration, Hunan University, Changsha 410082, China \\ Correspondence should be addressed to Kuan Yang; yangkuanhnu@163.com
}

Received 7 November 2019; Revised 2 March 2020; Accepted 16 March 2020; Published 24 April 2020

Academic Editor: Mosè Gallo

Copyright (C) 2020 Lin Tong et al. This is an open access article distributed under the Creative Commons Attribution License, which permits unrestricted use, distribution, and reproduction in any medium, provided the original work is properly cited.

Under the background of economic globalization, supply chain is becoming more and more complex, which is manifested in the instability of external environment. On the one hand, with the improvement of global environmental protection awareness, the government's policy tools for environmental impact (carbon tax) on the whole supply chain have become one of the major external problems faced by the supply chain enterprises; on the other hand, the intensification of competition between upstream and downstream in supply chains makes supply disruption an important proposition to be solved urgently. In this paper, the two propositions of green and supply disruption are reduced to two factors affecting the cost. The average total cost function of the manufacturer as a recycler is established. The practicability of the algorithm and the effectiveness of the model are verified by Lingo, Particle Swarm Optimization, and Genetic Algorithm, with the purpose of obtaining the optimal strategies for manufacturers who play the role of the recycler in the closed-loop supply chain.

\section{Introduction}

In recent years, managing supply chain through remanufacturing is an active research area, closed-loop supply chain management [1]. For the manufacturing industry, remanufacturing mitigating the deterioration of the environment to some extent not only increases resource utilization and promotes the increasing of social economic and the profits of enterprises but also improves the competitiveness of enterprises and shapes the corporate image [2]. At present, reverse logistics management has become the focus of many enterprises. Through recycling and remanufacturing activities, enterprises make themselves more competitive in product prices [3]. In the forward supply chain, the customer is the end of the supply chain. However, products that initially did not meet customer requirements still had residual value. Enterprises can release additional value from reverse logistics and remanufacturing processes to protect the environment. Through the combination of forward and reverse logistics management, the linear noncircular supply chain is transformed into closed-loop recycle.
Guo et al. [4] study the optimal strategies for the CLSC under supply disruption, and the influence of government subsidy mechanism on the business activities of enterprises in case of supply disruption is considered. Their article regards the cost caused by supply disruption as a part of the total cost of manufacturers, which is a great improvement on the total cost function of manufacturers as recyclers. But, with the increasingly prominent environmental problems and the increasing scarcity of natural resources, environmental protection has been deeply rooted among people. Green and sustainability have become an important symbol of enterprise competition, helping them to cope with the growing environmental pressure [5]. Globally, green cycle and low carbon development have become the trend. In the manufacturing industry, manufacturers are also affected by green policies: the existence of carbon tax policy makes manufacturers more inclined to recycle old products for remanufacturing because the cost of carbon tax in the process of remanufacturing products per unit is lower than that in the production process of new products per unit-which means that the cost of carbon tax has become 
an inevitable part of the total cost of manufacturers in the context of CLSC [6-8].

This article is a further study after the research of Guo et al. [4]. Thus, this article studies the optimal production strategy of the closed-loop supply chain in the context of carbon tax and supply disruption. Based on their research in [4], the cost of carbon tax has taken into consideration the total cost function for manufacturers; this will make the manufacturers as recyclers in the CLSC implement optimal production and recycling strategies according to the advanced cost structure in the current complex environment and get the maximum benefit. In addition, the hypothesis defined in [4] is that the recycling rate will decrease if the required quality level increases, so the quality of returned products is exponential distribution in their paper, $q \sim E(\lambda)$. But, in reality, when the quality level of recycled products $q$ is close to 0 , the product's residual value is almost 0 , so the product is more likely to be directly discarded rather than being recycled; when $q$ is close to 1 , the product's residual value is very high, and the product is more likely to be used by its owner-the quality of returned products is more suitable to be normal distribution. The main contributions and highlights of this study are as follows:

(i) Not only supply disruption but also carbon tax is considered in the CLSC system

(ii) The hypothesis of quality of returned products obeys normal distribution making it more real

\section{Literature Review}

This paper will next sort out the literature from three aspects: green sustainable closed-loop supply chain, comparison and selection of recycling channels, and closed-loop supply chain considering supply disruption.

2.1. Green and Sustainable Closed-Loop Supply Chain. All over the world, green cycle and low carbon development have become the trend of all walks of life, and closed-loop supply chain is no exception. Many contributions on the sustainable closed-loop supply chain are worked out. Paksoy et al. [9] developed a multiproduct closed-loop supply chain taking environmental impact into consideration. By adding cost factors on the basis of environment, Ma et al. [10] proposed a robust double objective green closed-loop supply chain design problem. Some scholars established a multiobjective green CLSC model to minimize the expected cost of the supply chain network and greenhouse gas emissions $[11,12]$. Bazan et al. [6] focused on two levels of CLSC, one for manufacturers and the other for retailers, with facilities for remanufacturing used goods. They considered three key environmental factors: (1) the materials consumed in manufacturing and remanufacturing activities, (2) the greenhouse gas emissions produced in production and transport activities, and (3) the items used for remanufacturing (recycling). Banasik et al. [13] established a multiobjective mixed integer linear programming model to quantify economic and environmental indicators and tried to find the balance between them. A multiobjective optimization mathematical model-developed by the $\mathrm{Na}$ tional University of the United States (NU), was tested by Nurjanni et al. [14], in order to find the best balance between economy and environment. Haddadisasakht and Ryan [15] put forward their own model based on carbon tax with uncertain tax rate. Wang and Guo [16] study the optimal operation strategy of multicycle hybrid manufacturing/ remanufacturing system considering carbon tax. Considering emissions of greenhouse gases and the overall operational cost, a green urban closed-loop logistics distribution network model is proposed in [7].

2.2. Selection of Recycling Channels. In recent years, many researches on closed-loop supply chain from different recycling channels are worked out. Generally speaking, they mainly study single-channel and multichannel recycling.

The relevant single-channel literature [17-24]is summarized in Table 1.

The relevant multichannel literatures: Yi and Yuan [25] coordinate and analyse the CLSC model of double-channel recycling that manufacturers and retailers can be recyclers. Hong et al. [26] constructed a model of manufacturer, retailer, and third-party mixed recycling and studied the selection of optimal mixed recycling mode. Giovanni and Zaccour [27] studied the different recycling channels of manufacturers and obtained the conditions for manufacturers to outsource the recycling business to retailers and third parties. Giovanni et al. [28] explored the incentive strategy model for both manufacturers and sellers to recycle waste products.

2.3. CLSC considering Supply Disruption. Supply chain disruption according to its causes can be divided as follows: (1) disruption by major unforeseen events and (2) disruption by operational accidents. The researchers propose corresponding recovery strategies for different disruptions.

Researchers' research achievements on disruption risk: Aryanezhad et al. [29] work out the design of supply chain when the distribution center is disturbed randomly and solve the disruption by developing a version of GA. The concept of P-Robust is applied in the design of reliable network model and measures to reduce disruption risk are implemented [30]. The model can run as normal (no disruption) after failure. Baghalian et al. [31] studied the demand-side uncertainty with probability function and the failure probability at the supply side of each factory in order to design the supply network of the Middle East agricultural food industry. Hernandez et al. [32] used the multiobjective optimization method to provide the decision-maker with the choice of the total weighted distance before and after the disruption. Disruption risk for robust decision-making is studied by Sawik [33]. In addition to the above, Asl-Najafi et al. [34] also researched the inventory design under interruption risk. Ghomi-Avili et al. [35] proposed a fuzzy biobjective bilevel model with a price-dependent demand for the network design in the presence of random disruptions at suppliers. Jabbarzadeh et al. [36] established a flexible CLSC network based on the consideration of lateral transfer as a 
TABLe 1: Single-channel recycling.

\begin{tabular}{|c|c|c|c|}
\hline Modes & Researcher & Time & Main research contents \\
\hline \multirow{3}{*}{ Manufacturer } & Polotski et al. & 2015 & Manufacturing and remanufacturing system production plan \\
\hline & Navin et al. & 2017 & $\begin{array}{c}\text { Considering manufacturing and remanufacturing, the problem of production planning in CLSC is } \\
\text { studied }\end{array}$ \\
\hline & Hariga et al. & 2017 & Minimizing the total chain cost \\
\hline \multirow{5}{*}{ Comparing } & Savaskan et al. & 2004 & $\begin{array}{c}\text { The pricing strategies and channel efficiency of different recovery modes in closed-loop supply } \\
\text { chain }\end{array}$ \\
\hline & $\begin{array}{l}\text { Wen and } \\
\text { Dong }\end{array}$ & 2016 & $\begin{array}{c}\text { Concluding that CSR and government incentives will promote producers to undertake recycling of } \\
\text { waste products }\end{array}$ \\
\hline & Chen and Tian & 2017 & $\begin{array}{c}\text { The optimal recovery mode selection of manufacturer and retailer under price fluctuation is } \\
\text { obtained }\end{array}$ \\
\hline & Hong et al. & 2012 & The optimality of retailer recycling by comparing retailer recycling with others \\
\hline & Wang and $\mathrm{Da}$ & 2010 & $\begin{array}{l}\text { The optimal decision-making of CLSC under retailer recycling and third-party recycling is } \\
\text { discussed }\end{array}$ \\
\hline
\end{tabular}

response strategy aiming at reducing the risk of operation and disruption. In this paper, the disruption of raw material supply generally refers to the failure of suppliers to meet customer needs on time [37]. The reason may be network disruption or infrastructure disruption.

In addition to the three parts in the abovementioned literature review, Saha et al. [38] investigate a reward-driven policy; three different modes of collection are employed. Mathematical models for both noncooperative and centralised scenarios are developed to characterise the pricing decisions and remanufacturing strategies. Nielsen et al. [39] study the different results of the three policy subsidies. The research shows that the results of the subsidy policy can bring benefits to consumers and increase the complexity of CLSC members to some extent. Network design and collective planning issues are also included in closed-loop supply chain planning.

In summary, the existing literature mostly studies the network design of CLSC under supply chain disruption and the recovery strategy after disruption or aimed to find the balance of environmental and economic objectives of green sustainable supply chain. Different from the existing literature, this paper combines the carbon tax and supply disruption to carry out relevant research under the recycling mode of manufacturers: manufacturers as recyclers, how to adjust the level of recycling quality to reduce their costs in the context of sustainable development; changes in government carbon tax policy, how to affect its cost at this time and how to formulate its recovery and production strategy; when considering the risk of supply disruption, how does the risk affect the manufacturer and how does the manufacturer formulate its strategy at this time. In research methods, Lingo, Particle Swarm Optimization, and Genetic Algorithm are used to verify the credibility and validity of the model.

The structure of this paper is as follows. In Section 3, the detailed problem description (assumptions, notations, and mathematical function with nine kinds of cost) is presented. The PSO and GA methodology which will be used in later analysis are introduced in Section 4. The numerical experiment and analyzes of the results are illustrated in Section 5. Finally, Section 6 has conclusions and deficiency.

\section{Problem Description}

The whole process in CLSC in this paper is shown in Figure 1.

\subsection{Assumptions}

(1) The quality of recycled products obeys normal distribution $[4,40]$.

(2) The demand is known (the demand rate remains unchanged).

(3) Remanufactured products and new products are homogeneous (the utility functions of consumers are the same) [41].

(4) In a cycle, raw materials are purchased once from material suppliers

(5) Buyback cost and remanufacturing cost are both functions of quality level of recycled products [42]

(6) All recycled products are not discarded

(7) The delivery time in manufacturing and remanufacturing processes is negligible

(8) The lead time is too difficult to be determined to be considered

(9) Assume that there is no shortage in the whole process

3.2. Notations. Considering a CLSC where the manufacturer is the recycler, the parameters are settled, as shown in Table 2.

3.3. Function. In the assumed closed-loop supply chain system, the total cost function of the manufacturer includes the following parts: (1) buyback cost, (2) remanufacturing cost, (3) raw material cost, (4) manufacturing cost, (5) inventory holding cost, (6) setup cost, (7) ordering cost, (8) carbon tax cost, and (9) supply disruption cost. Buyback cost, remanufacturing cost, inventory holding cost, carbon tax cost, and supply disruption cost will be detailed in Sections 3.3.1 3.3.5, respectively. The remaining costs are described in Section 3.3.6. 


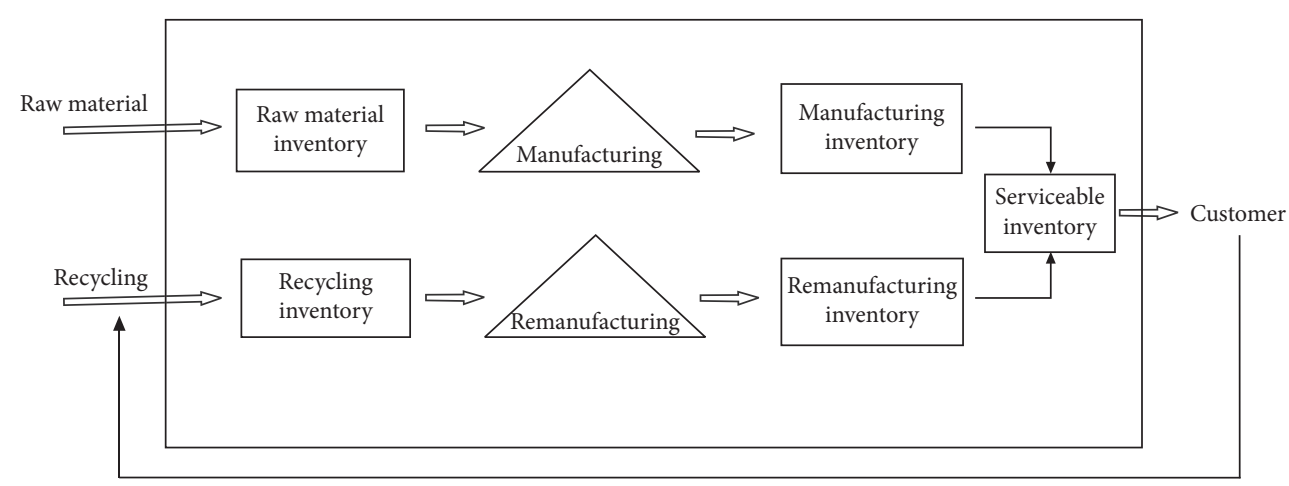

Figure 1: CLSC process.

TABLe 2: Parameter definition.

\begin{tabular}{|c|c|}
\hline Symbol & Meaning \\
\hline$a, \theta$ & Parameters of the buyback cost function \\
\hline$b, \psi$ & Parameters of the recycling rate function \\
\hline$c, \delta$ & Parameters of the remanufacturing cost function \\
\hline$D$ & Demand rate \\
\hline$(1-\beta) D$ & Manufacturing rate \\
\hline$(1-\gamma) D$ & Remanufacturing rate \\
\hline$d_{1}\left(d_{2}\right)$ & Purchasing cost per unit of raw materials charged by major (secondary) suppliers \\
\hline$C_{\text {raw }}$ & Purchasing cost for raw material per unit of one manufactured product \\
\hline$h_{\mathrm{s}}\left(h_{\mathrm{r}}, h_{\mathrm{raw}}\right)$ & Holding cost of serviceable (returned, raw materials) stock \\
\hline$C_{\mathrm{n}}$ & Manufacturing cost \\
\hline$P$ & Buyback cost ratio \\
\hline$D$ & Return rate \\
\hline$\Omega$ & Probability of supply disruption of major raw material suppliers \\
\hline A & Marginal recycling rate \\
\hline$S_{\mathrm{m}}\left(S_{\mathrm{n}}\right)$ & Installation cost for remanufacturing (manufacturing) \\
\hline$e_{\mathrm{m}}\left(e_{\mathrm{n}}\right)$ & The amount of carbon emissions from unit remanufactured (manufactured) goods \\
\hline$C_{1}$ & Cost of carbon tax per unit emission \\
\hline$T_{\mathrm{m}}\left(T_{\mathrm{n}}\right)$ & Time required to produce remanufactured (manufactured) products \\
\hline$C_{0}$ & Ordering cost \\
\hline
\end{tabular}

3.3.1. Buyback Cost. Recycling rate: $d=\alpha D$ is the recycling rate and $\alpha=b e^{-\varphi q}$ is the marginal recycling rate, $0 \leq b \leq 1$, referring to Vörös's paper [40] and a series of the study Guo et al. [4, 43]. In Vörös's paper, the recycling rate is inversely proportional to the quality level of recycled products [40]. Based on the assumptions above, the higher the quality level of recycled products is, the lower the remanufacturing cost is, but the price used to recycle products for companies becomes higher.

In this paper, the quality of returned items is assumed to be normal distribution. For convenience of calculation, we assume that the quality of returned products $q$ obeys the standard normal distribution, $q \sim N(0,1)$, and $x$ is the quality level of returned products $(q \leq x \leq 1)$ [16]. The probability density function of $x$ is as follows:

$$
X(x)= \begin{cases}\frac{1}{\sqrt{2 \pi}} e^{-x^{2} / 2}, & q<x<1, \\ 0, & \text { others. }\end{cases}
$$

Buyback cost ratio: considering the assumption that remanufactured products and new products are homogeneous to customers, buyback cost ratio $p$ is the ratio of return cost per unit of recycled goods to production cost per unit of new products (production cost includes raw material cost and manufacturing cost, $\left.C_{n}+C_{\text {raw }}\right) \cdot p$ is defined as $p=$ $a e^{-\theta(1-x)}, x \in[q, 1][4,16,40,43]$. If the required quality level is higher, $p$ will increase, as shown in Figure 2.

The average buyback cost is $V_{1}=d\left(C_{n}+C_{\text {raw }}\right) E(p)$ :

$$
\begin{aligned}
E(p)= & \int_{-\infty}^{+\infty} \frac{1}{\sqrt{2 \pi} e^{-x^{2} / 2}} a e^{-\theta(1-x)} \mathrm{d} x=a e^{\theta^{2}-2 \theta / 2} \int_{q}^{1} \\
& \cdot \frac{1}{\sqrt{2 \pi} e^{-(x-\theta)^{2} / 2}} \mathrm{~d} x \\
= & a e^{\theta^{2}-2 \theta / 2} \int_{q-\theta}^{1-\theta} \frac{1}{\sqrt{2 \pi}} e^{-(x-\theta)^{2} / 2} \mathrm{~d}(x-\theta) \\
= & a e^{\theta^{2}-2 \theta / 2}[\phi(1-\theta)-\phi(q-\theta)] .
\end{aligned}
$$




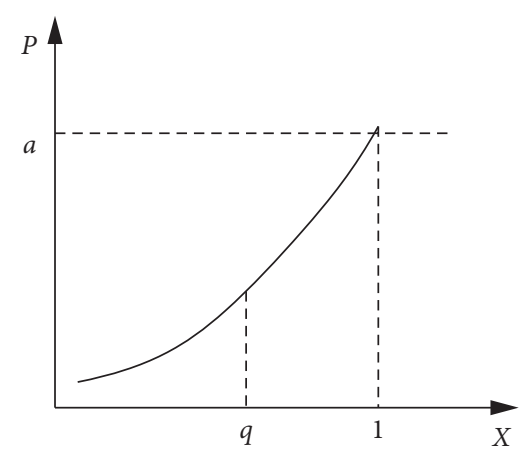

Figure 2: Buyback cost ratio $p$.

Thus,
$b e^{-\varphi q+\theta^{2}-2 \theta / 2}[\phi(1-\theta)-\phi(q-\theta)]$.

3.3.2. Remanufacturing Cost. The relationship between remanufacturing cost rate and product recovery quality is shown in Figure 3. Therefore, the remanufacturing cost ratio $s$ is defined as $s=c e^{\delta(1-x)}, x \in[q, 1][44]$.

The average remanufacturing cost is $V_{2}=d C_{n} E(s)$ :

$$
\begin{aligned}
E(s)= & \int_{-\infty}^{+\infty} \frac{1}{\sqrt{2 \pi} e^{-x^{2} / 2}} c e^{\delta(1-x)} \mathrm{d} x=c e^{\left(\delta^{2}+2 \delta\right) / 2} \int_{q}^{1} \\
& \cdot \frac{1}{\sqrt{2 \pi} e^{-(x+\delta)^{2} / 2}} \mathrm{~d} x \\
= & c e^{\left(\delta^{2}+2 \delta\right) / 2} \int_{q+\delta}^{1+\delta} \frac{1}{\sqrt{2 \pi} e^{-(x+\delta)^{2} / 2}} \mathrm{~d}(x+\delta) \\
= & c e^{\left(\delta^{2}+2 \delta\right) / 2}[\phi(1+\delta)-\phi(q+\delta)] .
\end{aligned}
$$

Thus,

$V_{2}=d C_{n} E(s)=c D C_{n} b e^{-\varphi q+\delta^{2}+2 \delta / 2}[\phi(1+\delta)-\phi(q+\delta)]$.

3.3.3. Inventory Holding Cost. The raw material inventory, the recycling inventory, and the serviceable inventorywhich include manufacturing inventory and remanufacturing inventory-compose the CLSC cycle. That is, one cycle $T$ contains $m$ manufacturing periods and $n$ remanufacturing periods assumed [43, 45].

For recycled goods with short life cycle, the value decreases with shelf time. Therefore, this model considers the first stage of remanufacturing of recycled goods and the second stage of manufacturing of new products. Figure 4 shows in detail the inventory.

Above all, we got the following.

The average inventory holding cost consists of the following four parts: (1) remanufacturing products' inventory cost $H_{m}$, (2) manufacturing products' inventory cost $H_{n}$, (3) recycling products' inventory cost $H_{r}$, and (4) raw materials' inventory cost $H_{s}$ :

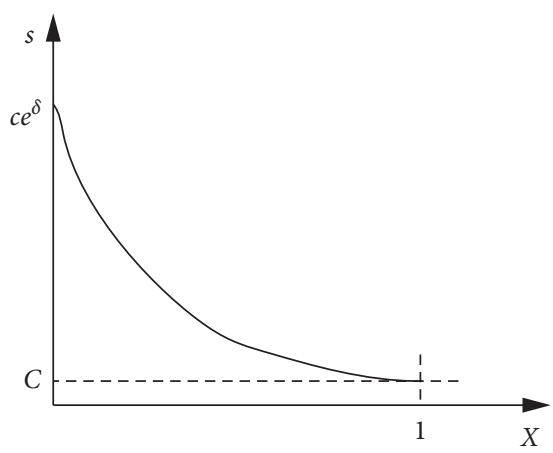

FIgURE 3: Remanufacturing cost $s$.

$$
\begin{aligned}
H_{m} & =\frac{1}{2} h_{s} I_{m} T_{m} \frac{1}{T}=\frac{1}{2} h_{s} * \frac{1}{m}(1-\gamma) \alpha D T * T_{m} \frac{1}{T} \\
& =\frac{1}{2 m^{2}} h_{s}(1-\gamma) \alpha^{2} D T, \\
H_{n} & =\frac{1}{2} h_{s} I_{n} T_{n} \frac{1}{T}=\frac{1}{2} h_{s} * \frac{1}{n}(1-\beta)(1-\alpha) D T * T_{n} \frac{1}{T} \\
& =\frac{1}{2 n^{2}} h_{s}(1-\beta)(1-\alpha)^{2} D T, \\
H_{r} & =\frac{1}{2} h_{r} I_{r} T \frac{1}{T}=\frac{1}{2} h_{r} \frac{\alpha}{m} D T[m(1-\alpha)+\alpha(1-\gamma)] \\
& =\frac{1}{2} h_{r}\left[\alpha(1-\alpha)+\frac{\alpha^{2}}{m}(1-\gamma)\right] D T, \\
H_{r} & =\frac{1}{2} h_{r} I_{r} T \frac{1}{T}=\frac{1}{2} h_{r} \frac{\alpha}{m} D T[m(1+\alpha)+\alpha((1+\gamma))] \\
H_{\text {raw }} & =h_{\text {raw }} S \frac{1}{T} \\
& =\frac{1}{2} h_{r}\left[\alpha(1-\alpha)+\frac{\alpha^{2}}{m}(1+\gamma)\right] D T, \\
& =\frac{1}{2}(1-\alpha)^{2} \frac{\beta+n-1}{n} D T T^{2}, \\
& \\
&
\end{aligned}
$$

In summary, the average inventory holding $\operatorname{cost} V_{3}$ is

$$
\begin{aligned}
V_{3}= & H_{m}+H_{n}+H_{r}+H_{\text {raw }} \\
= & \frac{1}{2 m^{2}} h_{s}(1-\gamma) \alpha^{2} D T+\frac{1}{2 n^{2}} h_{s}(1-\beta)(1-\alpha)^{2} D T \\
& +\frac{1}{2} h_{r}\left[\alpha(1-\alpha)+\frac{\alpha^{2}}{m}(1-\gamma)\right] D T \\
& +\frac{1}{2} h_{\text {raw }}(1-\alpha)^{2} \frac{\beta+n-1}{n} D T .
\end{aligned}
$$




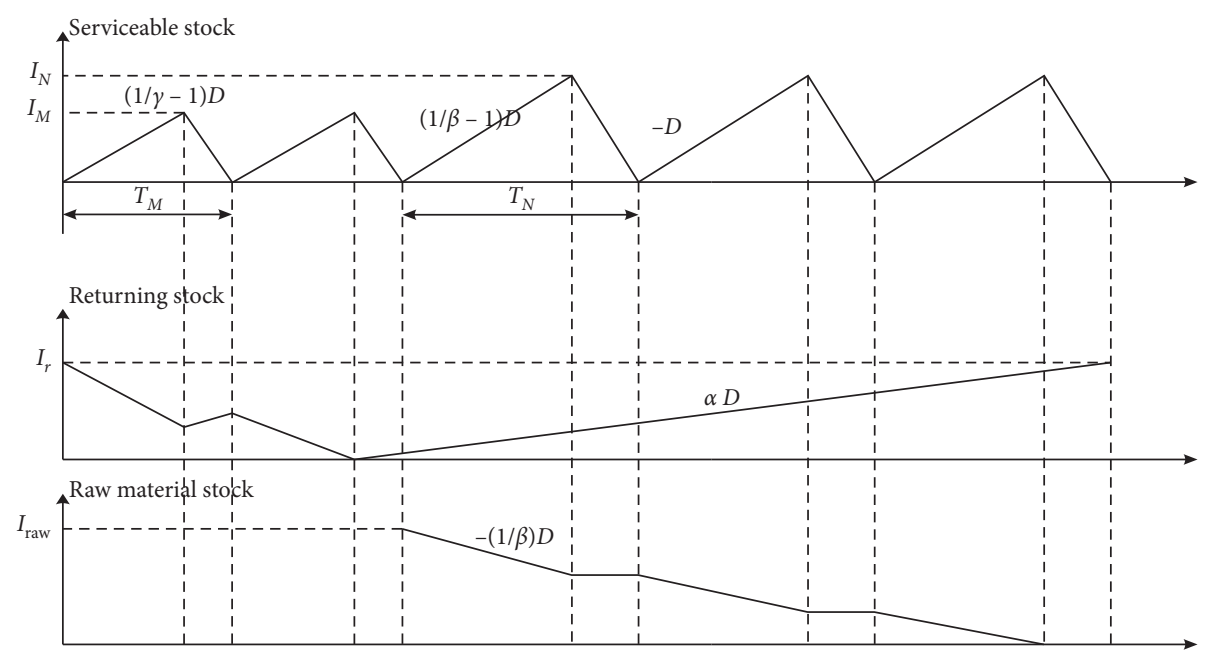

Figure 4: Inventory status.

3.3.4. Carbon Tax Cost. Remanufacturing is the implementation of high-tech repair and transformation of recycled old products, so the carbon emissions in remanufacturing process are much less than those in the production of completely new products, which is why remanufacturing has attracted much attention. In this article, we assume that carbon emissions per unit of remanufactured goods are $e_{x}$, manufactured ones are $e_{n}$, and $e_{x}<e_{n}$.

The average carbon tax cost is $V_{4}=\left(C_{1} / T\right)$ $\left[\alpha D e_{m}+(1-\alpha) D e_{n}\right]$.

3.3.5. Supply Disruption Cost. In a sustainable CLSC system, two levels of raw material suppliers, major suppliers and secondary suppliers, are considered. Because the cost of raw materials per unit charged by major suppliers is low, supply disruption is prone to occur.

Making use of the achievements of Guo and He [4], the average cost of supply disruption is shown as follows:

$$
V_{5}=(1-\omega)(1-\alpha) D d_{1}+\omega(1-\alpha) D d_{2} .
$$

The probability of disruption of raw materials supply by major suppliers is $\omega$; $d_{1}\left(d_{2}\right)$ is the purchasing cost per unit of raw materials charged by major (secondary) suppliers. Thus the cost for manufacturers to purchase raw materials from major suppliers is $(1-\omega)(1-\alpha) D d_{1}$, and it costs manufacturers $\omega(1-\alpha) D d_{2}$ from secondary suppliers due to the insufficient supply of the primary supplier.

3.3.6. Average Total Cost Function. Referring to the series of research worker of Guo et al. $[4,6,43,46]$, other costs are as follows.

The total demand is $D$ and the amount of $\alpha D$ is remanufactured by recycling, so the manufacturing quantity should be $(1-\alpha) D$. $C_{\text {raw }}$ is the purchasing cost for raw material per unit of a manufactured product.

Therefore,

(1) Manufacturing cost $V_{6}$ is $(1-\alpha) D C_{n}$.
(2) Raw materials' cost (raw materials here refer to the raw materials for manufacturing new products, which need to be purchased from suppliers) $V_{7}$ is $(1-\alpha) D C_{\text {raw }}$. $T$ means one cycle time of manufacturing and remanufacturing system. Suppose that a cycle includes producing $m$ remanufactured products and $n$ manufactured products; then $T$ can be expressed as $m T_{m}+n T_{n} . S_{m}$ represents the installation cost for remanufacturing while $S_{n}$ represents the manufacturing.

(3) Setup cost $V_{8}$ is $\left(m S_{m}+n S_{n}\right) / T$.

(4) Ordering cost $V_{9}$ can be expressed as $C_{0} / T$.

In the closed-loop system, in which the manufacturer acts as the recycler, the total cost function of the manufacturer consists of (1) buyback cost $V_{1}$, (2) remanufacturing cost $V_{2}$, (3) raw material cost $V_{7}$, (4) manufacturing cost $V_{6}$, (5) inventory holding cost $V_{3}$, (6) setup cost $V_{8}$, (7) ordering cost $V_{9}$, (8) carbon tax cost $V_{4}$, and (9) supply disruption cost $V_{5}$.

To sum up, the average total cost function is as follows:

$$
\begin{aligned}
\mathrm{ATC}= & V_{1}+V_{2}+V_{3}+V_{4}+V_{5}+V_{6}+V_{7}+V_{8}+V_{9} \\
= & a D\left(C_{n}+C_{\mathrm{raw}}\right) b e^{-\varphi q+\theta^{2}-2 \theta / 2}[\phi(1-\theta)-\phi(q-\theta)] \\
& +c D C_{n} b e^{-\varphi q+\delta^{2}+2 \delta / 2}[\phi(1+\delta)-\phi(q+\delta)]+(1-\alpha) D C_{n} \\
& +\frac{1}{2 m^{2}} h_{s}(1-\gamma) \alpha^{2} D T+\frac{1}{2 n^{2}} h_{s}(1-\beta)(1-\alpha)^{2} D T \\
& +\frac{1}{2} h_{r}\left[\alpha(1-\alpha)+\frac{\alpha^{2}}{m}(1-\gamma)\right] D T \\
& +\frac{1}{2} h_{\text {raw }}(1-\alpha)^{2} \frac{\beta+n-1}{n} D T+(1-\alpha) D C_{\text {raw }}+C_{0} / T \\
& +\left(m S_{m}+n S_{n}\right) / T \\
& +\frac{C_{1}}{T}\left[\alpha D e_{m}+(1-\alpha) D e_{n}\right]+(1-\omega)(1-\alpha) D d_{1} \\
& +\omega(1-\alpha) D d_{2} .
\end{aligned}
$$




\section{Optimization Algorithm}

PSO and GA are used to calculate the optimal value in this paper, avoiding limitation of each other. Meanwhile to verify that the model is built in green and sustainable CLSC, the computational results achieved by PSO, GA, and Lingo are worked out. This study first uses Lingo 11 to find the best solution. Lingo is an "interactive linear and general optimization solver," which is suitable for nonlinear programming or linear programming. Optimal model solutions usually use this method to obtain the best solution. Because the model in this paper is a linear problem, in this case the global optimal solution must be found, rather than the approximate optimal solution. The program is simple, has less code, and is faster. Secondly, in order to prove the feasibility of the model, a more mature Genetic Algorithm was selected, and binary coding was used to find a suitable solution. However, the Genetic Algorithm may have problems such as the cliff of Hamming. So the particle swarm algorithm is used which has an information sharing mechanism; that is to say, it is more enlightening than the Genetic Algorithm. It can avoid the shortcomings of Genetic Algorithm and analyze the calculation examples. The two algorithms have different convergence speeds. When two different calculation methods are used, the model and calculation results are better verified.

4.1. Genetic Algorithm. Genetic Algorithm (GA) is a global parallel search algorithm based on the idea of "survival of the fittest" biological evolution and heredity. The key parameters are population number, replication, crossover, and mutation probability.

Step 1 (encoding and initial population). Each chromosome in the algorithm consists of four variables ( $q$, $T, m$, and $n$ ), and a variable is represented by four binary codes. A chromosome is composed of 16 genotypes. The longer the chromosomes are, the higher the accuracy of calculation is. The first generation population was randomly generated, and the population size was 30 .

Step . (fitness function and selection operator). In fitness, the smaller the objective function value is, the higher the fitness value correspondingly is. Thus, the fitness function is $f(x)=1000 /$ objvalue, where "objvalue" presents the objective function value. In selection, individual chromosomes are selected and duplicated. It is more likely to select the chromosome with higher fitness. Then, the probability of chromosome selection is the roulette strategy which was used to select the population.
Step 3 (crossing and variation). Multipoint crossing is used to generate crossover bits randomly, and the crossover probability is used to judge whether the crossover exists or not. Variation of mutation sites is selected randomly according to the determined variation probability.

Step 4 (the termination rule). When the algorithm reaches the preset evolutionary algebra, this terminates the algorithm; otherwise, it is transferred to Step 2.

The main calculation process is as shown in Figure 5.

4.2. Particle Swarm Optimization Algorithm. In Particle Swarm Optimization (PSO), every particle in PSO represents the possible solution of a problem. Through the simple behavior of individual particles and the information interaction within the group, the intelligence of problem solving is realized. It has the characteristics of simple operation and fast convergence [47]. Guo and Ya [43] applied PSO to verify the cost model of the manufacturer. Guo et al. [46] applied PSO and GA to verify a logistics network under the environment of low carbon.

Step 1: first, each particle is given a random position and velocity. $X_{i}=(m, n, T, q)$ and the value of $i$ is $1 \sim 30$ defined.

Step 2: all particles will get a fitness value according to the objective function (ATC), which is defined as $\left(\mathrm{ATC}_{1} \sim \mathrm{ATC}_{30}\right)$. Then the Pbest is defined as the best position of each particle, and Gbest is defined as the best fitness value and position among the Pbest in all particles.

Step 3: update the position and velocity of 30 particles. If $x_{i}=r$ and $\geq 0.7$ or $v_{i}=r$ and $\geq 0.7$, the position and velocity of particles would be spontaneously updated.

Step 4: the objective function is run. After it all updated particles will get the new fitness value $\mathrm{ATC}_{1}^{\prime} \sim \mathrm{ATC}_{30}^{\prime}$.

Step 5: compare $\mathrm{ATC}_{1}^{\prime} \sim \mathrm{ATC}_{30}{ }^{\prime}$ with $\mathrm{ATC}_{1}^{\prime} \sim \mathrm{ATC}_{30}{ }^{\prime}$ and then select the best as the Pbest value of the particle.

Step 6: update the global best Gbest fitness value. Choose the best one from all the values of Gbest and Pbest.

Step 7: end the algorithm while the Gbest reaches the optimal value; otherwise return to Step 3 .

The main calculation process is as shown in Figure 6. 


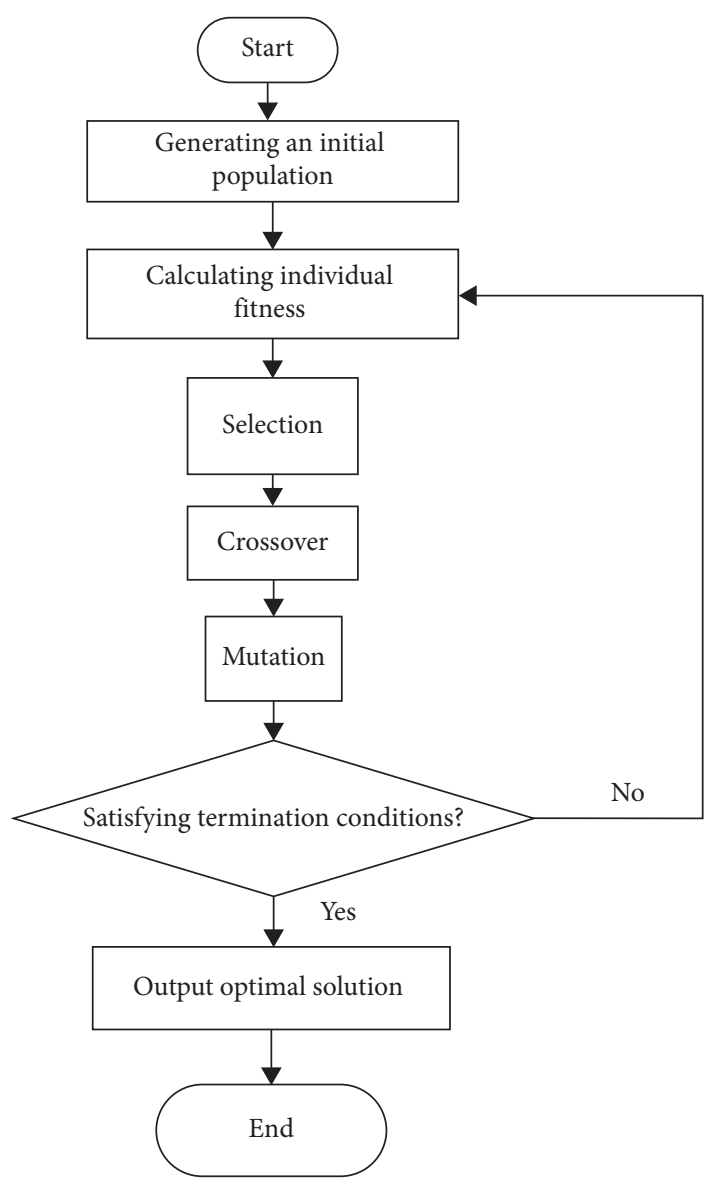

FIgURE 5: GA flow chart.

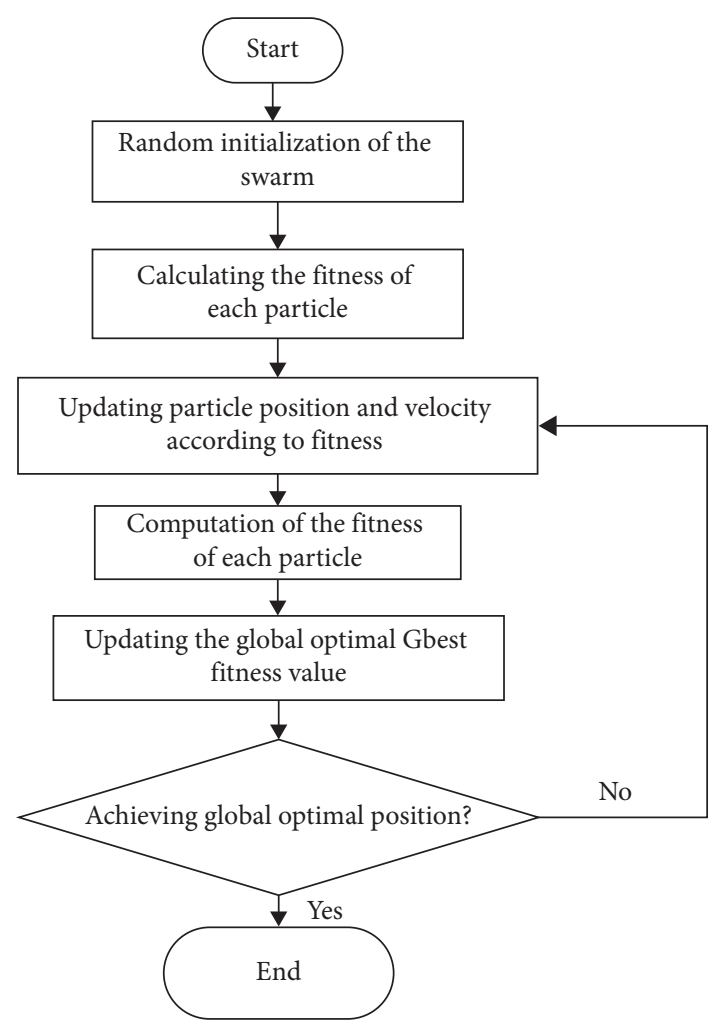

FIGURE 6: PSO flow chart.

\section{Numerical Examples}

5.1. Results. The numerical values of the parameters are as follows:

$$
\begin{aligned}
h_{s} & =1, \\
h_{r} & =0.2, \\
h_{\text {raw }} & =0.2, \\
C_{n} & =20, \\
C_{\text {raw }} & =10, \\
C_{0} & =1000, \\
S_{m} & =1500, \\
S_{n} & =1500, \\
D & =1000, \\
\varphi & =2, \\
\beta & =0.9, \\
\gamma & =0.1, \\
a & =0.9, \\
b & =0.1, \\
c & =0.9, \\
e_{n} & =0.5, \\
d_{1} & =20, \\
d_{2} & =28 .
\end{aligned}
$$

For different quality levels of recycled products (0.1 0.9), unit carbon emissions $e_{m}$ are shown in Table 3. Among them, the data refer to the relevant literature [48] and are sorted out. With various values of $\theta, \delta, C_{1}$, and $\omega$, different cases are studied. MATLAB language is used in the PSO and GA algorithms.

Table 4 shows the average total cost corresponding to different quality levels calculated by Lingo11 $\left(\theta=4, \delta=1, C_{1}=1\right.$, and $\left.\omega=0.2\right)$.

From Table $5(\mathrm{GAP}=(\mathrm{PSO}-\mathrm{GA}) / \mathrm{GA})$, it can be seen that, compared with the optimal value of Genetic Algorithm, Particle Swarm Optimization algorithm has achieved better results. Then, the results of Table 6 are obtained by comparing $\mathrm{PSO}$ with Lingo algorithm $(\mathrm{GAP}=(\mathrm{PSO}-\mathrm{Lingo}) /$ Lingo).

The sensitivity analysis results of supply disruption probability $\omega$ under the ratio of different remanufacturing and manufacturing times $(m: n)$ with parameters $\theta=4, \delta=$ $1, C_{1}=1$, and $q=0.3$ are shown in Table 7 . Table 8 is the total cost change of different carbon taxes under different ratios ( $m: n)$ when parameters $\theta=4, \delta=1, w=0.2$ and $q=3$.

\subsection{Analysis. We can draw the following conclusions.}

From Table 4, we can see that, with the increase of recycling quality, the ratio of remanufacturing times to manufacturing times $(m: n)$ increases gradually. Furthermore, the higher the recycling quality is, the shorter the 
TABLE 3: Unit carbon emissions of manufactured and remanufactured products.

\begin{tabular}{lccccccccc}
\hline Quality level $x$ & 0.1 & 0.2 & 0.3 & 0.4 & 0.5 & 0.6 & 0.7 & 0.8 & 0.9 \\
\hline$e_{x}$ & 0.3 & 0.3 & 0.25 & 0.25 & 0.2 & 0.2 & 0.15 & 0.1 & 0.1 \\
$e_{m}$ & 0.5 & & & & & & & & \\
\hline
\end{tabular}

TABle 4: Different quality levels of recycled products (Lingo).

\begin{tabular}{lccccc}
\hline$q$ & $e_{m}$ & $m$ & $n$ & $T$ & ATC \\
\hline 0.1 & 0.3 & 1 & 3 & 8.7697 & 49984.95 \\
0.2 & 0.3 & 1 & 3 & 8.7557 & 50476.73 \\
0.3 & 0.25 & 1 & 3 & 8.7347 & 50910.62 \\
0.4 & 0.25 & 1 & 2 & 7.6090 & 51144.72 \\
0.5 & 0.2 & 1 & 2 & 7.5882 & 51471.58 \\
0.6 & 0.2 & 1 & 2 & 7.5705 & 51751.41 \\
0.7 & 0.15 & 1 & 1 & 5.7485 & 51965.07 \\
0.8 & 0.1 & 1 & 1 & 5.7344 & 52166.07 \\
0.9 & 0.1 & 1 & 1 & 5.7232 & 52334.57 \\
\hline
\end{tabular}

manufacturing and remanufacturing cycle is. In this case, the increase of recycling cost is greater than the decrease of remanufacturing cost, so the ATC increases.

According to Tables 5 and 6 , from the perspective of algorithm and model, we can get the following: (1) whether it is PSO or GA algorithm, the difference between the two algorithms and Lingo optimal value is very small, which shows the effectiveness of the algorithm; (2) according to the change trend of ATC with parameters, it is found that the change trend of GA algorithm and PSO algorithm is the same, which proves the effectiveness of the model; (3) from the result of gap analysis, the gap between PSO algorithm and Lingo algorithm is smaller than that of GA algorithm, which shows that PSO algorithm is closer to the optimal value.

According to the results from Tables 5 and 6 , we can get management conclusions as follows:

(1) With the rise of $\theta$ (when $\delta$ and $m: n$ are still), $q$ and ATC will decrease and $T$ is longer; when $\theta$ is the same, $\delta$ increases, the ratio $m: n$ then diminishes, $q$ and ATC will ascend, and $T$ is shorter. In other words, if the remanufacturing cost remains unchanged, the quality level of the recycled product will be reduced and the total average cost too; in the case of constant buyback cost, the increase of remanufacturing cost will increase the total average cost and lead manufacturers to recycle higher quality recycled products. However, because of the recycle of highquality recycled products, the recycle cost will greatly increase, so manufacturers will increase the number of new products manufactured and reduce the number of remanufactures.

(2) $T$ is related to the proportion of remanufacturing and manufacturing $m: n$. When the proportion is smaller, this means that the number of remanufacturing times in a cycle is reduced (assuming that the number of manufacturing times is certain), so $T$ is shorter.
In summary, the optimal strategy for manufacturers at this time is to use products that meet the lowest level of remanufacturing quality for remanufacturing, so as to reduce ATC. After meeting the minimum quality level, manufacturers can consider reasonable planning of remanufacturing and manufacturing times to reduce costs (the ratio of optimal remanufacturing to manufacturing times in this example is $3: 1$ ).

From Tables 7 and 9, we can get some management recommendations.

(1) When the carbon tax remains unchanged and the quality level of recycled products remains unchanged $(C 1=1$ and $q=0.3)$, the average total cost increases with the increase of the probability of supply disruption (as shown in Table 7). Because the occurrence of supply disruption will affect the normal development of the downstream enterprises of the whole supply chain to a certain extent, the increase of the probability of supply disruption will bring more serious losses to the members of the supply chain (shown in Table 9).

(2) With the increase of $\omega$, we can see that $T$ also increases, which can be explained as follows. The increase in the probability of supply disruption may increase the manufacturing time $T_{n}$, so $T$ increases. Combined with Table 6, we can see that the cycle $T$ has a significant correlation with the proportion $m: n$ but has no significant relationship with the probability of supply disruption. This article focuses on the impact of supply disruption and carbon tax on ATC, so the impact of supply disruption and carbon tax on the cycle $T$ is no longer considered in the sensitivity analysis.

(3) Therefore, enterprises need to formulate and implement effective supply disruption risk prevention strategies to avoid the occurrence of supply disruption as far as possible, so as to make the production of enterprises go smoothly.

(4) However, the risk of supply disruption is unavoidable. Once supply disruption occurs, manufacturers should immediately adjust $x$ to the lowest level to meet the recycling requirements and adjust the proportion of remanufacturing and manufacturing times, so as to minimize the average total cost (in this case, when $q=0.1, m: n=1: 1$, the average total cost can reach the minimum value under supply disruption).

Table 8 examines the impact of different carbon taxes on total average costs when supply disruption risks remain unchanged and the quality level of recycled products is consistent $(\omega=0.2$ and $q=0.3)$. Table 10 shows the minimum average total cost and the best ratio $(m: n)$ under different recycling quality levels and different carbon taxes.

The managerial implications that can be derived from Tables 8 and 10 are as follows: 
Table 5: Comparison with PSO and GA $\left(C_{1}=1\right.$ and $\left.\omega=0.2\right)$.

\begin{tabular}{ccccccccccc}
\hline$\theta$ & $\delta$ & $m$ & $n$ & $q$ & $\begin{array}{c}T \\
\text { By PSO }\end{array}$ & ATC & $q$ & $\begin{array}{c}T \\
\text { By GA }\end{array}$ & ATC \\
\hline \multirow{4}{*}{4} & 0.5 & 3 & 1 & 0.1462 & 7.7849 & 50341.48 & 0.1491 & 7.4757 & 50342.24 & -0.0015 \\
& 1.0 & 2 & 1 & 0.2380 & 6.8362 & 50814.65 & 0.2281 & 3.7857 & 50964.41 & -0.2939 \\
& 1.5 & 1 & 1 & 0.3527 & 6.0158 & 50998.63 & 0.3538 & 6.7043 & 51018.26 & -0.0385 \\
\hline \multirow{3}{*}{5} & 0.5 & 3 & 1 & 0.1428 & 7.8051 & 50268.44 & 0.1407 & 7.1054 & 50269.32 & -0.0018 \\
& 1.0 & 2 & 1 & 0.2283 & 6.8513 & 50649.07 & 0.2033 & 4.2545 & 50712.07 & -0.1242 \\
& 1.5 & 1 & 1 & 0.3398 & 6.0643 & 50918.61 & 0.3342 & 6.6400 & 50930.37 & -0.0231 \\
\hline \multirow{3}{*}{6} & 0.5 & 3 & 1 & 0.1401 & 7.8142 & 50177.39 & 0.1305 & 7.2107 & 50185.33 & -0.0158 \\
& 1.0 & 2 & 1 & 0.2019 & 6.8725 & 50538.28 & 0.1976 & 4.9052 & 50569.56 & -0.0619 \\
& 1.5 & 1 & 1 & 0.3156 & 6.1547 & 50818.52 & 0.3112 & 5.8369 & 50821.60 & -0.0061 \\
\hline
\end{tabular}

TABle 6: Comparison with PSO and Lingo $\left(C_{1}=1\right.$ and $\left.\omega=0.2\right)$.

\begin{tabular}{|c|c|c|c|c|c|c|c|c|c|c|}
\hline$\theta$ & $\delta$ & $m$ & $n$ & $q$ & $\begin{array}{c}T \\
\text { By PSO }\end{array}$ & ATC & $q$ & $\begin{array}{c}T \\
\text { By Lingo }\end{array}$ & ATC & GAP $(\%)$ \\
\hline \multirow{3}{*}{4} & 0.5 & 3 & 1 & 0.1462 & 7.7849 & 50341.48 & 0.1490 & 7.6681 & 50340.98 & 0.0010 \\
\hline & 1.0 & 2 & 1 & 0.2380 & 6.8362 & 50814.65 & 0.2279 & 6.8026 & 50652.63 & 0.3199 \\
\hline & 1.5 & 1 & 1 & 0.3527 & 6.0158 & 50998.63 & 0.3521 & 5.8209 & 50996.85 & 0.0035 \\
\hline \multirow{3}{*}{5} & 0.5 & 3 & 1 & 0.1428 & 7.8051 & 50268.44 & 0.1430 & 7.6724 & 50267.02 & 0.0028 \\
\hline & 1.0 & 2 & 1 & 0.2283 & 6.8513 & 50649.07 & 0.2176 & 6.8079 & 50581.30 & 0.1340 \\
\hline & 1.5 & 1 & 1 & 0.3398 & 6.0643 & 50918.61 & 0.3311 & 5.8263 & 50906.37 & 0.0240 \\
\hline \multirow{3}{*}{6} & 0.5 & 3 & 1 & 0.1401 & 7.8142 & 50177.39 & 0.1395 & 7.6749 & 50156.28 & 0.0421 \\
\hline & 1.0 & 2 & 1 & 0.2019 & 6.8725 & 50538.28 & 0.2033 & 6.8153 & 50513.62 & 0.0488 \\
\hline & 1.5 & 1 & 1 & 0.3156 & 6.1547 & 50818.52 & 0.3188 & 5.8295 & 50812.12 & 0.0126 \\
\hline
\end{tabular}

TABLe 7: Result of sensitivity test on different supply disruption probability $\omega\left(\theta=4, \delta=1, C_{1}=1\right.$, and $\left.q=0.3\right)$.

\begin{tabular}{|c|c|c|c|c|}
\hline$\omega$ & $m$ & $n$ & $T$ & ATC \\
\hline \multirow{5}{*}{0} & 3 & 1 & 6.8874 & 49660.97 \\
\hline & 2 & 1 & 6.4235 & 49453.46 \\
\hline & 1 & 1 & 6.0123 & 49222.59 \\
\hline & 1 & 2 & 6.7939 & 49253.50 \\
\hline & 1 & 3 & 7.6967 & 49398.43 \\
\hline \multirow{5}{*}{0.2} & 3 & 1 & 6.9025 & 51173.16 \\
\hline & 2 & 1 & 6.4356 & 50965.65 \\
\hline & 1 & 1 & 6.0258 & 50734.78 \\
\hline & 1 & 2 & 6.8342 & 50765.69 \\
\hline & 1 & 3 & 7.7014 & 50910.62 \\
\hline \multirow{5}{*}{0.4} & 3 & 1 & 7.0134 & 52685.35 \\
\hline & 2 & 1 & 6.4922 & 52477.84 \\
\hline & 1 & 1 & 6.0305 & 52246.97 \\
\hline & 1 & 2 & 6.8901 & 52277.88 \\
\hline & 1 & 3 & 7.7233 & 52422.81 \\
\hline \multirow{5}{*}{0.6} & 3 & 1 & 7.0279 & 54197.54 \\
\hline & 2 & 1 & 6.5138 & 53990.03 \\
\hline & 1 & 1 & 6.0366 & 53759.16 \\
\hline & 1 & 2 & 6.9280 & 53790.07 \\
\hline & 1 & 3 & 7.7614 & 53935.00 \\
\hline \multirow{5}{*}{0.8} & 3 & 1 & 7.0401 & 55709.73 \\
\hline & 2 & 1 & 6.5313 & 55502.22 \\
\hline & 1 & 1 & 6.0419 & 55271.35 \\
\hline & 1 & 2 & 6.9847 & 55302.26 \\
\hline & 1 & 3 & 7.8432 & 55447.19 \\
\hline \multirow{5}{*}{1.0} & 3 & 1 & 7.0496 & 57221.92 \\
\hline & 2 & 1 & 6.6003 & 57014.41 \\
\hline & 1 & 1 & 6.0485 & 56783.54 \\
\hline & 1 & 2 & 7.2360 & 56814.45 \\
\hline & 1 & 3 & 7.9659 & 56959.38 \\
\hline
\end{tabular}

TABLe 8: Result of sensitivity test on different carbon tax $C_{1}(\omega=0.2$ and $q=0.3)$.

\begin{tabular}{|c|c|c|c|}
\hline$C_{1}$ & $m$ & $n$ & ATC \\
\hline \multirow{5}{*}{1} & 3 & 1 & 51173.16 \\
\hline & 2 & 1 & 50965.65 \\
\hline & 1 & 1 & 50734.78 \\
\hline & 1 & 2 & 50765.69 \\
\hline & 1 & 3 & 50910.62 \\
\hline \multirow{5}{*}{2} & 3 & 1 & 51236.35 \\
\hline & 2 & 1 & 51036.11 \\
\hline & 1 & 1 & 50816.00 \\
\hline & 1 & 2 & 50828.18 \\
\hline & 1 & 3 & 50965.42 \\
\hline \multirow{5}{*}{3} & 3 & 1 & 51297.64 \\
\hline & 2 & 1 & 51003.96 \\
\hline & 1 & 1 & 50893.34 \\
\hline & 1 & 2 & 50888.37 \\
\hline & 1 & 3 & 51018.56 \\
\hline \multirow{5}{*}{4} & 3 & 1 & 51357.19 \\
\hline & 2 & 1 & 51169.48 \\
\hline & 1 & 1 & 50967.31 \\
\hline & 1 & 2 & 50946.48 \\
\hline & 1 & 3 & 51070.21 \\
\hline \multirow{5}{*}{5} & 3 & 1 & 51415.15 \\
\hline & 2 & 1 & 51232.90 \\
\hline & 1 & 1 & 51038.31 \\
\hline & 1 & 2 & 51002.73 \\
\hline & 1 & 3 & 51120.46 \\
\hline
\end{tabular}

(1) With the increase of carbon tax, the average total cost rises gradually. Therefore, the total carbon emissions should be considered as much as possible in the 
TABLE 9: Optimal operational strategies (different supply disruption probability when $C_{1}=3$ ).

\begin{tabular}{|c|c|c|c|c|}
\hline$q$ & $\omega$ & $m$ & $n$ & ATC \\
\hline \multirow{3}{*}{0.1} & 0 & 1 & 1 & 48487.33 \\
\hline & 0.5 & 1 & 1 & 52159.83 \\
\hline & 1 & 1 & 1 & 55832.34 \\
\hline \multirow{3}{*}{0.2} & 0 & 1 & 2 & 48961.05 \\
\hline & 0.5 & 1 & 2 & 52692.92 \\
\hline & 1 & 1 & 2 & 56424.79 \\
\hline \multirow{3}{*}{0.3} & 0 & 1 & 2 & 49376.18 \\
\hline & 0.5 & 1 & 2 & 53156.65 \\
\hline & 1 & 1 & 2 & 56937.13 \\
\hline \multirow{3}{*}{0.4} & 0 & 1 & 2 & 49740.23 \\
\hline & 0.5 & 1 & 2 & 53560.56 \\
\hline & 1 & 1 & 2 & 57380.77 \\
\hline \multirow{3}{*}{0.5} & 0 & 1 & 2 & 50054.45 \\
\hline & 0.5 & 1 & 2 & 53907.29 \\
\hline & 1 & 1 & 2 & 57760.14 \\
\hline \multirow{3}{*}{0.6} & 0 & 1 & 2 & 50324.39 \\
\hline & 0.5 & 1 & 2 & 54203.91 \\
\hline & 1 & 1 & 2 & 58083.43 \\
\hline \multirow{3}{*}{0.7} & 0 & 1 & 2 & 50553.36 \\
\hline & 0.5 & 1 & 2 & 54454.72 \\
\hline & 1 & 1 & 2 & 58356.08 \\
\hline \multirow{3}{*}{0.8} & 0 & 1 & 2 & 50746.65 \\
\hline & 0.5 & 1 & 2 & 54665.89 \\
\hline & 1 & 1 & 2 & 58585.13 \\
\hline \multirow{3}{*}{0.9} & 0 & 1 & 2 & 50909.08 \\
\hline & 0.5 & 1 & 2 & 54842.96 \\
\hline & 1 & 1 & 2 & 58776.84 \\
\hline
\end{tabular}

production operation of enterprises, and the total cost should be reduced by adjusting the ratio of remanufacturing times to manufacturing times in the production process. (In this case, when carbon $\operatorname{tax}$ is 1 or 2 , the best ratio of remanufacturing times to manufacturing times is $1: 1$ making the average total cost reach the optimum state; when carbon tax is greater than 2 and less than or equal to 5 , the best ratio of remanufacturing times to manufacturing times is $1: 2$, shown in Table 10 and Figure 7.)

(2) If the government wants to promote remanufacturing, it can consider decreasing carbon tax reasonably, to encourage manufacturers to increase the ratio of remanufacturing times to manufacturing times.

(3) For the carbon tax value set by the government, enterprises can choose the optimal production strategy to minimize the average total cost according to the recycling quality level (in this case, when $C_{1}=3$, enterprises can choose the best ratio $m: n=$ 1: 1 under the quality level $q=0.1$ or choose the best ratio $m: n=1: 2$ under the quality level $q \geq 0.2$, shown in Table 10).

(4) The optimal strategy of enterprises is to control the proportion of remanufacturing times and manufacturing times reasonably according to the
TABLE 10: Optimal operational strategies (different carbon taxes $\omega=0.2)$.

\begin{tabular}{|c|c|c|c|c|}
\hline$q$ & $C_{1}$ & $m$ & $n$ & ATC \\
\hline \multirow{3}{*}{0.1} & 1 & 1 & 1 & 49800.18 \\
\hline & 3 & 1 & 1 & 49956.33 \\
\hline & 5 & 1 & 2 & 50073.48 \\
\hline \multirow{3}{*}{0.2} & 1 & 1 & 1 & 50297.21 \\
\hline & 3 & 1 & 2 & 50453.80 \\
\hline & 5 & 1 & 2 & 50567.90 \\
\hline \multirow{3}{*}{0.3} & 1 & 1 & 1 & 50734.78 \\
\hline & 3 & 1 & 2 & 50888.37 \\
\hline & 5 & 1 & 2 & 51002.73 \\
\hline \multirow{3}{*}{0.4} & 1 & 1 & 1 & 51116.41 \\
\hline & 3 & 1 & 2 & 51268.34 \\
\hline & 5 & 1 & 2 & 51383.55 \\
\hline \multirow{3}{*}{0.5} & 1 & 1 & 1 & 51445.18 \\
\hline & 3 & 1 & 2 & 51595.58 \\
\hline & 5 & 1 & 2 & 51711.15 \\
\hline \multirow{3}{*}{0.6} & 1 & 1 & 1 & 51726.57 \\
\hline & 3 & 1 & 2 & 51876.20 \\
\hline & 5 & 1 & 2 & 51992.46 \\
\hline \multirow{3}{*}{0.7} & 1 & 1 & 1 & 51965.07 \\
\hline & 3 & 1 & 2 & 52113.90 \\
\hline & 5 & 1 & 2 & 52230.51 \\
\hline \multirow{3}{*}{0.8} & 1 & 1 & 1 & 52166.24 \\
\hline & 3 & 1 & 2 & 52314.72 \\
\hline & 5 & 1 & 2 & 52431.88 \\
\hline \multirow{3}{*}{0.9} & 1 & 1 & 1 & 52334.57 \\
\hline & 3 & 1 & 2 & 52482.63 \\
\hline & 5 & 1 & 2 & 52600.08 \\
\hline
\end{tabular}

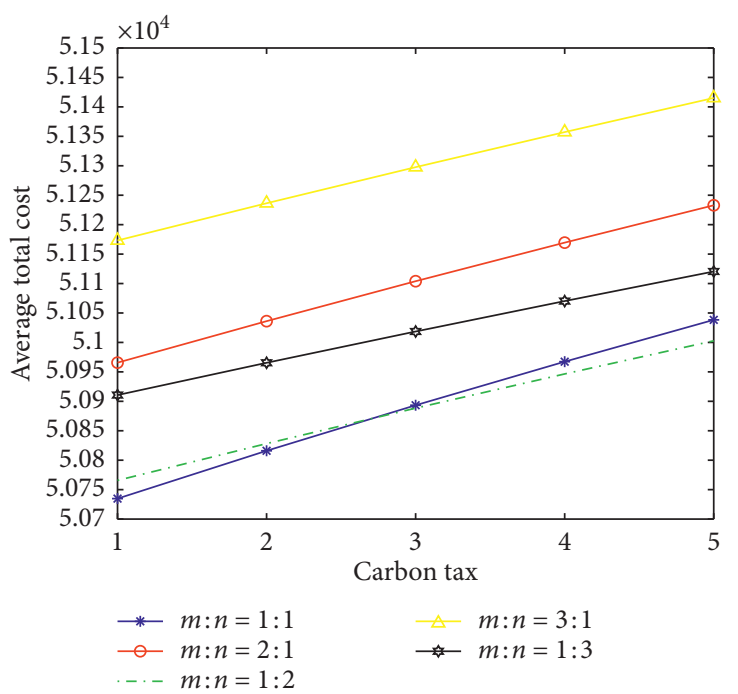

FIGURE 7: Average total cost fluctuation chart with different carbon taxes.

quality level of recycled products in the model and the relevant policies of the government, so as to minimize the average total cost. The setting of carbon tax value needs to take into account the interests of enterprises. Only by pursuing the balance point of economic interests and environmental protection 
interests can the government and enterprises achieve a win-win situation.

(5) What is interesting is that we get a result that seems to be contrary to our expectation: with the increase of carbon tax, the ratio $m: n$ should also increase (the increase of carbon tax means that remanufactured products is more advantageous than new products in the cost of carbon tax, so theoretically enterprises will increase the number of remanufacturing times only considering the carbon tax), but in fact we get that the value of $m: n$ corresponding to the minimum total average cost decreases with the increase of carbon tax. The reason may be that, in our numerical example, the carbon tax cost per unit of remanufactured goods and its average inventory holding cost increase more than the carbon tax cost of manufactured goods and the average inventory holding cost of manufactured goods increase, so the carbon tax increases and the remanufacturing and manufacturing ratio decreases.

\section{Conclusions and Recommendations}

The optimal recovery and production strategy of manufacturers as recyclers in a sustainable CLSC considering carbon tax and supply disruption are studied. We assume that the recovery quality level obeys the standard normal distribution. The average total cost function of the manufacturer is established and the cost model considering environment and supply disruption and its corresponding algorithm are proved by Lingo, PSO, and GA. Through numerical examples, we analyze the effects of supply disruption risk and carbon tax policy on the optimal production and recycling strategies for manufacturers; then, the optimal strategies are given.

With the rise of supply interruption probability, ATC of the system will increase. Once supply interruption occurs, it will bring serious losses to the operation of the enterprise. In the process of recovery and production, enterprises can adjust the quality level of recycled products according to carbon tax, rationally arrange remanufacturing and manufacturing batches to reduce their ATC, and actively deal with the problem of supply disruption.

Further research direction is to reduce the constraints of hypothetical conditions (random market demand, considering the discarding and shortage of recycled goods, etc.).

\section{Data Availability}

The data used to support the findings of this study are included within the article.

\section{Conflicts of Interest}

The authors declare that they have no conflicts of interest.

\section{Acknowledgments}

This work was supported by the Ministry of Education's Humanities and Social Sciences Project (17YJA630119).

\section{References}

[1] C. T. Zhang and M. L. Ren, "Closed-loop supply chain coordination strategy for the remanufacture of patented products under competitive demand," Applied Mathematical Modelling, vol. 40, no. 13-14, pp. 6243-6255, 2016.

[2] A. Shakourloo, A. Kazemi, and M. O. M. Javad, "A new model for more effective supplier selection and remanufacturing process in a closed-loop supply chain," Applied Mathematical Modelling, vol. 40, no. 23-24, pp. 9914-9931, 2016.

[3] A. Yenipazarli, "Managing new and remanufactured products to mitigate environmental damage under emissions regulation," European Journal of Operational Research, vol. 249, no. 1, pp. 117-130, 2016.

[4] J. Guo, H. Lu, and M. Gen, "Optimal strategies for the closedloop supply chain with the consideration of supply disruption and subsidy policy," Computers \& Industrial Engineering, vol. 128, pp. 886-893, 2018.

[5] P. C. Sauer and S. Stefan, "Extending the reach of multi-tier sustainable supply chain management-insights from mineral supply chains," International Journal of Production Economics, vol. 217, pp. 31-43, 2018.

[6] E. Bazan, M. Y. Jaber, and S. Zanoni, "Carbon emissions and energy effects on a two-level manufacturer-retailer closedloop supply chain model with remanufacturing subject to different coordination mechanisms," International Journal of Production Economics, vol. 183, pp. 394-408, 2017.

[7] J. Wang, M. K. Lim, M.-L. Tseng, and Y. Yang, "Promoting low carbon agenda in the urban logistics network distribution system," Journal of Cleaner Production, vol. 211, pp. 146-160, 2019.

[8] L. Zhen, L. Huang, and W. Wang, "Green and sustainable closed-loop supply chain network design under uncertainty," Journal of Cleaner Production, vol. 227, pp. 1195-1209, 2019.

[9] T. Paksoy, N. Y. Pehlivan, and E. Özceylan, "Fuzzy multiobjective optimization of a green supply chain network with risk management that includes environmental hazards," Human and Ecological Risk Assessment: An International Journal, vol. 18, no. 5, pp. 1120-1151, 2012.

[10] R. Ma, L. Yao, M. Jin, P. Ren, and Z. Lv, "Robust environmental closed-loop supply chain design under uncertainty," Chaos, Solitons \& Fractals, vol. 89, pp. 195-202, 2016.

[11] L. Ameknassi, D. Aït-Kadi, and N. Rezg, "Integration of logistics outsourcing decisions in a green supply chain design: a stochastic multi-objective multi-period multi-product programming model," International Journal of Production Economics, vol. 182, pp. 165-184, 2016.

[12] M. Fazli-Khalaf, A. Mirzazadeh, and M. S. Pishvaee, "A robust fuzzy stochastic programming model for the design of a reliable green closed-loop supply chain network," Human and Ecological Risk Assessment: An International Journal, vol. 23, no. 8, pp. 2119-2149, 2017.

[13] A. Banasik, A. Kanellopoulos, G. D. H. Claassen, J. M. Bloemhof-Ruwaard, and J. G. A. J. van der Vorst, "Closing loops in agricultural supply chains using multiobjective optimization: a case study of an industrial mushroom supply chain," International Journal of Production Economics, vol. 183, pp. 409-420, 2017. 
[14] K. P. Nurjanni, M. S. Carvalho, and L. Costa, "Green supply chain design: a mathematical modeling approach based on a multi-objective optimization model," International Journal of Production Economics, vol. 183, no. B, pp. 421-432, 2017.

[15] A. Haddadsisakht and S. M. Ryan, "Closed-loop supply chain network design with multiple transportation modes under stochastic demand and uncertain carbon tax," International Journal of Production Economics, vol. 195, pp. 118-131, 2018.

[16] X. Y. Wang and J. Q. Guo, "Subsidy strategy model of multiperiod closed-loop hybrid system under carbon tax," Computer Engineering and Applications, vol. 54, no. 14, pp. 236240, 2018.

[17] V. Polotski, A. Kenne, and A. Gharbi, "Optimal production scheduling for hybrid manufacturing-remanufacturing systems with setups," Journal of Manufacturing Systems, vol. 37, no. 3, pp. 703-714, 2015.

[18] K. D. Navin, R. Shankar, and A. Choudhary, "Strategic design for inventory and production planning in closed-loop hybrid systems," International Journal of Production Economics, vol. 183, pp. 345-353, 2017.

[19] M. Hariga, Z. R. As'ad, and Z. Khan, "Manufacturingremanufacturing policies for a centralized two stage supply chain under consignment stock partnership," International Journal of Production Economics, vol. 183, pp. 362-374, 2017.

[20] R. C. Savaskan, S. Bhattacharya, and L. N. Van Wassenhove, "Closed-loop supply chain models with product remanufacturing," Management Science, vol. 50, no. 2, pp. 239-252, 2004.

[21] W. Xiao-qin and Y.-R. Dong, "A study on recycling mode selection in the reverse logistics with consideration of corporate social responsibility," Operations Research and Management Science, vol. 25, no. 1, pp. 275-281, 2016.

[22] J. Chen and D.-G. Tian, "Selection of the recycling mode based on closed-loop supply chain model," Chinese Journal of Management Science, vol. 25, no. 1, pp. 88-97, 2017.

[23] I.-H. Hong and J.-S. Yeh, "Modeling closed-loop supply chains in the electronics industry: a retailer collection application," Transportation Research Part E: Logistics and Transportation Review, vol. 48, no. 4, pp. 817-829, 2012.

[24] W. B. Wang and Q. L. Da, "The study on collection and pricing for closed-loop supply chain with retailer and the third party collecting," Journal of Industrial Engineering and Engineering Management, vol. 24, no. 2, pp. 130-134, 2010.

[25] Y. X. Yi and J. Yuan, "Pricing coordination in closed-loop supply chain with hybrid recovery channel," Business Review, vol. 23, no. 11, pp. 169-176, 2011.

[26] X. Hong, Z. Wang, D. Wang, and H. Zhang, "Decision models of closed-loop supply chain with remanufacturing under hybrid dual-channel collection," The International Journal of Advanced Manufacturing Technology, vol. 68, no. 5-8, pp. 1851-1865, 2013.

[27] P. D Giovanni and G. Zaccour, "A two-period game of a closed-loop supply chain,” European Journal of Operational Research, vol. 232, no. 1, pp. 22-40, 2014.

[28] P. D. Giovanni, P. V. Reddy, and G. Zaccour, "Incentive strategies for an optimal recovery program in a closed-loop supply chain," European Journal of Operational Research, vol. 249 , no. 2, pp. 605-617, 2016.

[29] M.-B. Aryanezhad, S. G. Jalali, and A. Jabbarzadeh, “An integrated supply chain design model with random disruptions consideration," African Journal of Business Management, vol. 4, no. 12, pp. 2393-2401, 2010.

[30] P. Peng, A. Snyder, and Z. Liu, "Reliable logistics networks design with facility disruptions," Transportation Research Part B: Methodological, vol. 45, no. 8, pp. 1190-1211, 2011.
[31] A. Baghalian, S. Rezapour, and R. Z. Farahani, "Robust supply chain network design with service level against disruptions and demand uncertainties: a real-life case," European Journal of Operational Research, vol. 227, no. 1, pp. 199-215, 2013.

[32] I. Hernandez, J. Emmanuel Ramirez-Marquez, C. Rainwater, E. Pohl, and H. Medal, "Robust facility location: hedging against failures," Reliability Engineering \& System Safety, vol. 123, pp. 73-80, 2014.

[33] T. Sawik, "On the robust decision-making in a supply chain under disruption risks," International Journal of Production Research, vol. 52, no. 22, pp. 6760-6781, 2014.

[34] J. Asl-Najafi, B. Zahiri, A. Bozorgi-Amiri, and A. TaheriMoghaddam, "A dynamic closed-loop location-inventory problem under disruption risk," Computers \& Industrial Engineering, vol. 90, pp. 414-428, 2015.

[35] M. Ghomi-Avili, S. G. Jalali Naeini, R. Tavakkoli-Moghaddam, and A. Jabbarzadeh, "A fuzzy pricing model for a green competitive closed-loop supply chain network design in the presence of disruptions," Journal of Cleaner Production, vol. 188, pp. 425-442, 2018.

[36] A. Jabbarzadeh, M. Haughton, and A. Khosrojerdi, "Closedloop supply chain network design under disruption risks: a robust approach with real world application," Computers \& Industrial Engineering, vol. 116, pp. 178-191, 2018.

[37] M. J. Braunscheidel and N. C. Suresh, "The organizational antecedents of a firm's supply chain agility for risk mitigation and response," Journal of Operations Management, vol. 27, no. 2, pp. 119-140, 2009.

[38] S. Saha, S. P. Sarmah, and I. Moon, "Dual channel closed-loop supply chain coordination with a reward-driven remanufacturing policy," International Journal of Production Research, vol. 54, no. 5, pp. 1503-1517, 2016.

[39] I. E. Nielsen, S. Majumder, and S. Saha, "Game-theoretic analysis to examine how government subsidy policies affect a closed-loop supply chain decision," Applied Sciences, vol. 10, no. 1, p. $145,2020$.

[40] J. Vörös, "Product balancing under conditions of quality inflation, cost pressures and growth strategies," European Journal of Operational Research, vol. 141, no. 1, pp. 153-166, 2002.

[41] N. Hamta, S. M. T. Fatemi Ghomi, F. Jolai, and M. Akbarpour Shirazi, "A hybrid pso algorithm for a multi-objective assembly line balancing problem with flexible operation times, sequencedependent setup times and learning effect," International Journal of Production Economics, vol. 141, no. 1, pp. 99-111, 2013.

[42] J. Wang, J. Zhao, and X. Wang, "Optimum policy in hybrid manufacturing/remanufacturing system," Computers \& Industrial Engineering, vol. 60, no. 3, pp. 411-419, 2011.

[43] J. Guo and G. Ya, "Optimal strategies for manufacturing/remanufacturing system with the consideration of recycled products," Computers \& Industrial Engineering, vol. 89, pp. 226-234, 2015.

[44] L. I. Xin-jun, "Monopoly production optimization model for remanufacturing cost with stochastic distribution and market segmentation," Chinese Management Science, vol. 15, no. 5, pp. 72-77, 2007.

[45] I. Dobos and K. Richter, "An extended production/recycling model with stationary demand and return rates," International Journal of Production Economics, vol. 90, no. 3, pp. 311-323, 2004.

[46] J. Guo, X. Wang, and M. S. Gen, "Forward and reverse logistics network and route planning under the environment of low-carbon emissions: a case study of Shanghai fresh food e-commerce enterprises," Computers \& Industrial Engineering, vol. 106, pp. 351-360, 2017. 
[47] M. A. Mohandes, "Modeling global solar radiation using Particle Swarm Optimization (PSO)," Solar Energy, vol. 86, no. 11, pp. 3137-3145, 2012.

[48] C. H. Yang, H. Liu, P. Ji et al., "Optimal acquisition and remanufacturing policies for multi-product remanufacturing systems," Journal of Cleaner Production, vol. 135, pp. 15711579, 2015. 